Journal of Telenursing (JOTING)

Volume 2, Nomor 2, Desember 2020

e-ISSN: 2684-8988

p-ISSN: 2684-8996

DOI: https://doi.org/10.31539/joting.v2i2.1409

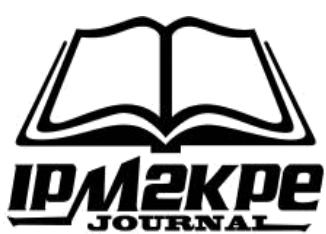

\title{
FREKUENSI PERNAFASAN ANAK PENDERITA ASMA MENGGUNAKAN INTERVENSI TIUP SUPER BUBBLES DAN MENIUP BALING BALING BAMBU
}

\author{
Harsismanto $\mathrm{J}^{1}$, Padila ${ }^{2}$, Juli Andri ${ }^{3}$, Muhammad Bagus Andrianto ${ }^{4}$, \\ Lussyefrida Yanti ${ }^{5}$ \\ Universitas Muhammadiyah Bengkulu ${ }^{1,2,3,4,5}$ \\ harsismanto@gmail.com ${ }^{1}$
}

\begin{abstract}
ABSTRAK
Tujuan dari penelitian ini adalah untuk mengetahui perbandingan tiup super bubbles dan meniup baling baling bambu terhadap frekuensi pernafasan anak penderita asma di Ruang Edelweis RSUD DR. M. Yunus Bengkulu Tahun 2019. Desain penelitian yang digunakan adalah penelitian quasy eksperimen. Hasil analisis univariat diperoleh Frekuensi pernapasan sebelum dan setelah melakukan terapi tiup super bubbles ratarata dalam kategori sedang $(26,91)$ dan setelah intervensi dalam kategori sedang $(25,30)$. Rata-rata frekuensi pernapasan sebelum dan setelah dilakukan meniup balingbaling bambu sedang $(26,69)$ dan ringan $(24,81)$. Hasil analisis bivariat menunjukkan ada pengaruh tiup super bubbles terhadap frekuensi pernafasan pada anak dengan $\mathrm{p}$ value $=0,000$ dan ada pengaruh meniup baling-baling bambu terhadap frekuensi pernafasan pada anak penderita asma dengan nilai $p$ value $=0,007$. Simpulan, tidak ada perbedaan efektifitas diberikan terapi tiup super bubbels dengan meniup baling-baling bambu pada anak penderita asma.
\end{abstract}

Kata Kunci: Baling-Baling Bambu, Frekuensi Pernafasan, Tiup Super bubbles

\begin{abstract}
This study aimed to see the comparison of blowing bubbles and blowing bamboo blades to the respiratory frequency of children with asthma in the Edelweiss Room, DR. M. Yunus Bengkulu Year 2019. The research design used was a quasi-experimental research. The univariate analysis results showed that the average respiratory rate before and after doing super bubble blow therapy was in the moderate category (26.91) and after the intervention was in the medium type (25.30). The average respiratory frequency before and after blowing the bamboo propeller was moderate (26.69) and light (24.81). The bivariate analysis results showed that there was an effect of blowing bubbles on respiratory frequency in children with a value of $p=0.000$, and there was an effect of blowing bamboo propellers on respiratory frequency in children with asthma with a value of $p=0.007$. In conclusion, there is no difference in superbubbles blowing therapy's effectiveness by blowing bamboo propellers in children with asthma.
\end{abstract}

Keywords: Bamboo Propeller, Respiratory Frequency, Blow Super bubbles 


\section{PENDAHULUAN}

Kesehatan adalah investasi untuk keberhasilan pembangunan bangsa, dengan tujuan untuk membangun dan meningkatkan kesadaran, kemauan dan kemampuan hidup sehat bagi setiap orang agar terwujud derajat kesehatan masyarakat yang setinggitingginya. Sehat adalah suatu keadaan sejahtera yang meliputi fisik, mental dan sosial yang tidak hanya bebas dari penyakit atau kecacatan. Masalah kesehatan yang paling sering dialami seperti hipertensi, penyakit jantung, stroke dan diabetes melitus, asma, penyakit sendi (rematik dan asam urat), kanker/tumor, dan cedera lalu lintas darat (Kemenkes, 2016).

Jumlah penderita penyakit asma mencapai lebih $27 \%$ banyak perempuan dari pada laki-laki yang hanya mencapai $14 \%$. Untuk anak perempuan, penyakit asma yang diderita tidak mengalami penurunan karena pada saat beranjak dewasa, pada perempuan mengalami penyempitan saluran pernafasan hingga 20\%. Akan tetapi, saat ini kejadian asma lebih banyak pada laki-laki akibat polusi asap rokok (Primadyastuti, 2017)

Laporan organisasi kesehatan dunia (WHO) dalam world health report 2016 menyebutkan, lima penyakit paru utama merupakan $17,4 \%$ dari seluruh kematian di dunia, masing-masing terdiri dari infeksi paru 7,2\%, PPOK (Penyakit Paru Obstruksi Kronis) $4,8 \%$, tuberkulosis 3,0\%, kanker paru/trakea/bronkus 2,1\% dan asma $0,3 \%$. Global Initiative for Asthma (GINA) memperkirakan 300 juta penduduk dunia menderita asma. Prevalensi total asma di dunia diperkirakan $6 \%$ pada dewasa dan $10 \%$ pada anak (Infodatin, 2017).

Berdasarkan hasil Survey Kesehatan Rumah Tangga (SKRT) asma merupakan penyebab kematian (mortalitas) keempat di Indonesia atau sebesar 5,6\%. Dilaporkan prevalensi asma di seluruh Indonesia sebesar 13 per 1.000 penduduk. Kejadian asma terbanyak di Provinsi Sulawesi Tengah yaitu $7,8 \%$ dan di Nusa Tenggara Timur yaitu 7,3\%, sedangkan di Provinsi Bengkulu angka kejadian asma yaitu 2,0\% (Kemenkes, 2017).

Penelitian yg dilakukan oleh National Health Interview Survey bersama memanfaatkan kuesioner ISAAC (International Study on Asthma and Allergy in Children), mengatakan bahwa akibat dari asma yang tidak ditangani dengan tepat dapat menyebabkan kematian. Penelitian tersebut mengatakan bahwa asma merupakan penyebab kematian kedelapan dari data yg ada di Indonesia prevalensi gejala penyakit asma melonjak dari 4,2\% jadi 5,4\% (Hardina \& Wulandari, 2019).

Penyebab penyakit asma ada kaitannya dengan antibody tubuh yang memiliki kepekaan berlebih terhadap alergen dalam hal ini adalah Imunoglobulin (Ig) E. Sedangkan alergen yang dimaksud disini dapat berupa alergen intrinsik maupun ekstrinsik. Sehingga penyakit asma ini dapat menurun dari orang tua kepada keluarganya (Kowalak et al., 2011; Padila, 2012; Padila et al., 2019). Faktor keturunan ini juga bisa menyebabkan terjadinya gangguan pada perkembangan anak (Padila et al., 2019; Panzilion et al., 2020).

Penyakit asma pada anak perlu penanganan yang baik dari tenaga kesehatan karena penyakit tersebut bisa dialami terus menerus oleh anak bahkan sampai dewasa, oleh karena itu perlu adanya terapi yang dapat diberikan pada anak, baik terapi farmakologis maupun terapi non farmakologis. Terapi non farmakologis yang bisa diberirikan pada anak adalah purse lips breathing.

Pursed lips breathing adalah strategi yang digunakan dalam rehabilitasi pulmonal untuk menurunkan sesak napas. Pasien dengan gangguan pernapasan akan mendapatkan keuntungan bila menggunakan teknik ini. Strategi ini dibuat dengan tujuan untuk 
membantu pasien mengontrol pola napas, meningkatkan ventilasi pola napas, meningkatkan mekanisme batuk efektif, mencegah atelektasis, meningkatkan kekuatan otot pernapasan, meningkatkan relaksasi dan mencegah terjadinya kekambuhan dan sesak napas (Dechman, 2011).

Terapi lain yang bisa diberikan adalah terapi bermain meniup super bubbels merupakan permainan yang memerlukan inspirasi dalam dan ekspirasi yang memanjang. Tujuan terapi ini adalah melatih pernapasan yaitu ekspirasi menjadi lebih panjang dari pada inspirasi untuk memfasilitasi pengeluaran karbondioksida dari tubuh yang tertahan karena obstruksi jalan napas. Terapi bermain meniup super bubbels ditujukan untuk anak-anak yang mengalami gangguan pada sistem pernapasan khususnya asma dengan tujuan agar fungsi paru pada anak akan meningkat dan menjadi normal (Hockenbery, 2009).

Berdasarkan data dari RSUD dr. M. Yunus Bengkulu jumlah kejadian asma setiap tahunnya mengalami penurunan yaitu pada tahun 2015 sebanyak 129 orang, pada tahun 2016 sebanyak 72 orang dan pada tahun 2017 sebanyak 71 orang. Berdasarkan survey awal yang dilakukan pada tanggal 11 September 2018 di RSUD dr. M. Yunus Bengkulu terdapat 16 pasien penderita asma yang berusia 2-5 tahun dan wawancara yang dilakukan pada perawat di ruangan tersebut belum terdapat terapi non farmakologi pada penderita asma seperti terapi tiup super bubbels dan meniup baling-baling bambu (RSUD Dr. M. Yunus Bengkulu, 2018).

\section{METODE PENELITIAN}

Penelitian ini menggunakan rancangan quasy eksperimen, pre-test dan post-test two group desaign dilakukan di Ruang Edelweis RSUD DR. M. Yunus Bengkulu. Waktu penelitian pada tanggal 19 Januari sampai dengan 19 Februari 2019. Populasi dalam penelitian ini yaitu seluruh pasien penderita asma di Ruang Edelweis RSUD DR. M. Yunus Bengkulu pada bulan September tahun 2017 berjumlah 22 orang selama 1 bulan. Sampel diambil sebanyak 20 orang, yang diambil dengan teknik purposive berdasarkan kriteria insklusi dan ekslusi yang terbagi menjadi dua kelompok yaitu 10 orang diberi terapi super bubbels dan 10 orang diberi terapi baling-baling bambu. Data primer yaitu data yang diperoleh langsung dari pasien dan data sekunder yaitu data yang diperoleh dari dokumen-dokumen, laporan-laporan.

\section{HASIL PENELITIAN Analisa Univariat}

Tabel. 1

Rata-Rata Frekuensi Pernafasan pada Anak Penderita Asma Sebelum dan Setelah Melakukan Terapi Tiup Super bubbles

\begin{tabular}{cccc}
\hline Super Bubbels & Rata-rata & Frekuensi & Persentase \\
\hline Frekuensi Pernafasan Pre & & & \\
Sedang & 26,91 & 10 & 100,0 \\
Ringan & & 0 & 0,0 \\
\hline Total & & 10 & 100,0 \\
\hline Frekuensi Pernafasan Post & 25,30 & 8 & 80,0 \\
Sedang & & 2 & 20,0 \\
Ringan & & 10 & 100,0 \\
\hline Total &
\end{tabular}

Sumber: Data Primer yang sudah diolah (2019) 
Berdasarkan tabel 1 dapat diketahui frekuensi pernapasan sebelum melakukan terapi tiup super bubbles rata-rata frekuensi pernapasan yaitu sedang $(26,91)$ dan setelah dilakukan tiup super bubbles rata-rata frekuensi pernafasan sedang $(25,30)$ di Ruang Edelweis RSUD DR. M. Yunus Bengkulu.

Tabel. 2

Rata-Rata Frekuensi Pernafasan pada Anak Penderita Asma Sebelum dan Setelah Melakukan Terapi Meniup Baling Baling Bambu

\begin{tabular}{cccc}
\hline Meniup Baling-Baling Bambu & Rata-Rata & Frekuensi & Persentase \\
\hline Frekuensi Pernafasan Pre & & & \\
Sedang & 25,69 & 7 & 70,0 \\
Ringan & & 3 & 30,0 \\
\hline Total & & 10 & 100,0 \\
\hline Frekuensi Pernafasan Post & 24,81 & 4 & 40,0 \\
Sedang & & 6 & 60,0 \\
Ringan & & 10 & 100,0 \\
\hline Total
\end{tabular}

Sumber: Data Primer yang sudah diolah (2019)

Berdasarkan tabel 2 dapat diketahui frekuensi pernapasan sebelum melakukan terapi meniup baling-baling bambu rata-rata frekuensi pernapasan yaitu ringan $(26,69)$ dan setelah dilakukan meniup baling-baling bambu rata-rata frekuensi pernafasan ringan $(24,81)$ di Ruang Edelweis RSUD DR. M. Yunus Bengkulu.

\section{Analisa Bivariat}

Tabel. 3

Pengaruh Frekuensi Pernafasan pada Anak Penderita Asma

Sebelum dan Setelah Dilakukan Terapi Tiup Super Bubbles

\begin{tabular}{ccccc}
\hline Variabel & $\mathrm{N}$ & Std. Deviation & Ratio Interval & P Value \\
\hline Frekuensi pernafasan sebelum & \multirow{2}{*}{10} & 0,90363 & & \\
\cline { 1 - 1 } Frekuensi pernafasan setelah & & 1,24900 & $1.10591-2,11409$ & 0,000
\end{tabular}

Sumber: Data Primer yang sudah diolah (2019)

Berdasarkan tabel 3 didapatkan bahwa dari hasil uji statistik didapatkan nilai $\mathrm{p}$ value $=0,000$, maka dapat disimpulkan bahwa ada pengaruh tiup super bubbles terhadap frekuensi pernafasan pada anak pada penderita asma di Ruang Edelweis RSUD DR. M. Yunus Bengkulu.

Tabel. 4

Pengaruh Frekuensi Pernafasan pada Anak Penderita Asma Sebelum dan Setelah Dilakukan Terapi Meniup Baling-Baling Bambu

\begin{tabular}{ccccc}
\hline Variabel & $\mathrm{N}$ & Std. Deviation & Ratio Interval & $P$ Value \\
\hline Frekuensi pernafasan sebelum & \multirow{2}{*}{10} & 25.6900 & & \\
\cline { 1 - 3 } Frekuensi pernafasan setelah & & 24.8100 & $0,30692-1,45308$ & 0,007
\end{tabular}

Sumber: Data Primer yang sudah diolah (2019) 
Berdasarkan tabel 4 didapatkan bahwa dari hasil uji statistic didapatkan nilai $\mathrm{p}$ value $=0,007$, maka dapat disimpulkan bahwa ada pengaruh meniup baling-baling bambu terhadap frekuensi pernafasan pada anak pada penderita asma di Ruang Edelweis RSUD DR. M. Yunus Bengkulu.

Tabel. 5

Perbandingan Tiup Super Bubbles dan Meniup Baling Baling Bambu terhadap Frekuensi Pernafasan Anak Usia Prasekolah Penderita Asma

\begin{tabular}{ccccccc}
\hline Variabel & Mean & $\begin{array}{c}\mathrm{t} \\
\text { hitung }\end{array}$ & $\mathrm{N}$ & $\begin{array}{c}\text { Std. } \\
\text { Deviation }\end{array}$ & $95 \% \mathrm{CI}$ & $\begin{array}{c}P \\
\text { Value }\end{array}$ \\
\hline $\begin{array}{c}\text { Super bubbels } \\
\text { Bambu }\end{array}$ & 1.610 & & 10 & 0,704 & $-0,1478-$ & 0,108 \\
& 1.000 & 1.691 & & 0,896 & 1,3678 & \\
\hline
\end{tabular}

Sumber: Data Primer yang sudah diolah (2019)

Berdasarkan tabel 6 didapatkan bahwa dari uji Independen nilai signifikansi lebih besar dari 0,05 yaitu 0,108, sehingga terapi super bubbels dan meniup baling-baling bambu memiliki varian yang sama. Berdasarkan hasil uji statistik di dapatkan nilai $\mathrm{t}$ hitung $>\mathrm{t}$ tabel $(1,691>2,101)$ dengan nilai $\mathrm{p}=0,108$ maka artinya tidak ada perbedaan tingkat frekuensi pernafasan diberikan terapi tiup super bubbels dengan meniup balingbaling bambu pada anak penderita asma di Ruang Edelweis RSUD DR. M. Yunus Bengkulu Tahun 2019.

\section{PEMBAHASAN}

Berdasarkan hasil penelitian diketahui bahwa frekuensi pernapasan sebelum melakukan terapi tiup super bubbles rata-rata frekuensi pernapasan yaitu sedang $(26,91)$ dan setelah dilakukan tiup super bubbles rata-rata frekuensi pernafasan sedang $(25,30)$ di Ruang Edelweis RSUD DR. M. Yunus Bengkulu. Hal ini menunjukkan bahwa terapi nonfarmakologi dengan tiup super bubbles mengalami perubahan frekuensi.

Hasil penelitian ini sejalan dengan penelitian Junaidin et al., (2019) yang menyebutkan bahwa terjadi penurunan frekuensi pernafasan setelah diberikan terapi tiup balon, hal ini dikarenakan karena terapi super bubbles dan tiup balon memberikan terapi distraksi yang bermanfaat untuk membuka aliran udara paru sehingga mengurangi sesak napas, selain menjadi terapi distraksi usaha meniup super bubbles melatih kemampuan pengembangan paru dan kapasitas udara paru, yang meningkatkan efektifitas pernapasan anak, yang membuat penurunan frekuensi napas pada anak asma.

Berdasarkan hasil penelitian diketahui bahwa frekuensi pernapasan sebelum melakukan terapi meniup baling-baling bambu rata-rata frekuensi pernapasan yaitu ringan $(26,69)$ dan setelah dilakukan meniup baling-baling bambu rata-rata frekuensi pernafasan ringan $(24,81)$ di Ruang Edelweis RSUD DR. M. Yunus Bengkulu, hal ini diketahui bahwa rata-rata frekuensi pernafasan mengalami penurunan frekuensi meskipun dalam kategori tidak terdapat perubahan yang dipengaruhi oleh anak yang kurang bersedia berpartisipasi untuk meniup baling-baling bambu.

Hasil ini sejalan dengan penelitian Sutini (2015) yang mengatakan bahwa terapi meniup baling-baling bambu untuk mengurangi sesak pada pendeita asma sangat efektif untuk melancarkan sirkulasi udara paru, karena terapi ini termasuk kedalam terapi distraksi dan relaksasi yang bertujuan mengatur pernapasan. 
Berdasarkan hasil penelitian dengan melakukan uji statistik t-dependen didapatkan bahwa ada pengaruh tiup super bubbles terhadap frekuensi pernafasan pada anak pada penderita asma di Ruang Edelweis RSUD DR. M. Yunus Bengkulu. Hal ini menunjukkan bahwa penyakit tiup super bubbles memiliki peranan dalam penurunan frekuensi pernafasan, sehingga terjadi perubahan pada frekuensi pernapasan anak yang mengalami asma. Pasien asma mengalami penyempitan jalan nafas karena hiperaktivitas terhadap rangsangan tertentu, yang menyebabkan peradangan dan penyempitan ini bersifat sementara.

Terapi bermain meniup super bubbels merupakan permainan yang memerlukan inspirasi dalam dan ekspirasi yang memanjang. Dalam keperawatan terapi ini masuk dalam jenis terapi pursed lips breating. Tujuan terapi ini adalah melatih pernapasan yaitu ekspirasi menjadi lebih panjang dari pada inspirasi untuk memfasilitasi pengeluaran karbondioksida dari tubuh yang tertahan karena obstruksi jalan napas. Terapi bermain meniup super bubbels ditujukan untuk anak-anak yang mengalami gangguan pada sistem pernapasan khususnya asma dengan tujuan agar fungsi paru pada anak akan meningkat dan menjadi normal (Isnainy \& Tias, 2019).

Super bubbles yaitu permainan yang terbuat dari bahan sabun cair atau deterjen yang nantinya akan ditiup secara perlahan dan menghasilkan gelembung. Peneliti menggunakan terapi bermain super bubbles karena terapi bermain super bubbles selain memberikan distraksi juga memberikan relaksasi saat anak meniup gelembung secara perlahan yang berdampak dengan membukanya aliran udara menjadi besar sehingga dapat mengurangi sesak (Widiyatmoko \& Wulanningrum, 2018).

Hasil penelitian ini sejalan dengan Isnaini (2015) menyebutkan bahwa pemberian terapi bermain meniup super bubbles terhadap status oksigenisasi pada anak asma Usia Prasekolah di Ruang Melati 2 RSUD Moerwodadi Surakarta. Status oksigenisasi yang baik dapat menurunkan frekuensi sesak yang dialamu anak, sehingga serangan asma pada anak dapat berkurang.

Bermain meniup baling-baling bambu merupakan suatu permainan atau aktivitas yang memerlukan inspirasi dalam dan ekspirasi memanjang dengan mulut dimonyongkan, ini dilakukan pada pasien dengan penyakit pernafasan terutama asma. Menipu baling-baling bambu dapat memperbaiki kelenturan atau fleksibilitas ronggo dada sehingga dapat mengambang dan mengempis secara optimal, memperbaiki kelenturan dan kekuatan diafragma (sekat rongga-badan). Berdasarkan penelitian Sutini (2015) terapi meniup seperti bermain baling-baling bambu dan super bubbels dapat dilakukan selama 5 menit dengan 15 kali tiupan yang dilakukan selama dilakukan 5 detik selama 3 hari. Bahan yang digunakan yaitu bambu dan pipet.

Berdasarkan hasil uji independen menunjukkan terapi super bubbels dan meniup baling-baling bambu memiliki varian yang sama. tidak ada perbedaan tingkat frekuensi pernafasan diberikan terapi tiup super bubbels dengan meniup baling-baling bambu pada anak penderita asma di Ruang Edelweis RSUD DR. M. Yunus Bengkulu Tahun 2019.

Bermain meniup balon dan baling-baling bambu dapat menlancarkan aliran udara menjadi besar terutama selama ekspirasi, hal ini menyebabkan terjadi penurunan volume ekspirasi paksa atau Forced Expiration Volume (FEV1) dan Arus puncak ekspirasi (APE), sehingga dapat menurunkan frekuensi nafas penderita asma (Nur, et al., 2019). 


\section{SIMPULAN}

Ada pengaruh tiup super bubbles terhadap frekuensi pernafasan pada anak dan ada pengaruh meniup baling-baling bambu terhadap frekuensi pernafasan pada anak penderita asma. Tidak ada perbedaan efektifitas diberikan terapi tiup super bubbels dengan meniup baling-baling bambu pada anak penderita asma.

\section{SARAN}

Diharapkan klien mengetahui penyebab terjadinya asma dan cara mencegah kekambuhan asma dengan melakukan terapi mandiri seperti tiup super bubbels dan tiup baling-baling bambu.

\section{DAFTAR PUSTAKA}

Dechman, D. (2011). Still Counting Biodiversity Exploration for Conservation: The First 20 Years of the Rapid Assesment Program. Arlington: Conservation International

Hardina, S., \& Wulandari, D. (2019). Pengaruh Konsumsi Air Hangat terhadap Frekuensi Nafas pada Pasien Asma di Puskesmas Sukamerindu Kota Bengkulu Tahun 2019. Journal of Nursing And Public Health, 7(2), 77-86

Hockenberry, M. J., \& Wilson, D. (2009). Essential of Pediatric Nursing. St. Louis Missoury: Mosby

Infodatin. (2017). Pusat Data dan Informasi Kesehatan RI. Jakarta: ISSN 2442-7659

Isnaini, I. (2015). Pemberian Terapi Bermain Meniup terhadap Status Oksigenisasi pada anak Usia Prasekolah di Ruang Melati 2 RSUD Moerwodadi Surakarta. http://digilib.stikeskusumahusada.ac.id/files/disk1/27/01-gdl-annaisnain-1325-1ktianna-7.pdf

Isnainy, U. C. A. S., \& Tias, S. A. (2019). Pengaruh Posisi Condong ke Depan dan Terapi Pursed LIPS Breathing terhadap Derajat Sesak Napas Penderita Penyakit Paru Obstruktif Kronik (PPOK). Holistik Jurnal Kesehatan, 13(4), 389-395

Junaidin, J., Syam, Y., \& Irwan, A. M. (2019). The Effect of Pursed Lip Breathing and Balloon Blowing on the Strength of Respiratory Muscle, Oxygen Saturation and Respiratory Rate in Copd Patients. Jurnal Ilmiah Keperawatan (Scientific Journal of Nursing), 5(1), 31-39

Kemenkes. (2016). Infodatin Asma. Kemenkes RI: Jakarta

Kemenkes. (2017). Hasil Penelitian Riset Kesehatan Dasar. Indonesia: Kemenkes RI

Kowalak., J. P, Welsh., \& Mayer, B. (2011). Buku Ajar Patofisiologi. Jakarta: EGC

Nur, A., Amin, M., Sajidin, M., \& Kusnanto, K. (2019). Gambaran Arus Puncak Ekspirasi (APE) dan Kontrol Asma pada Pasien Asma. Jurnal Penelitian Kesehatan Suara Forikes, 10(3), 193-198

Panzilion, P., Padila, P., Amin, M., \& Andri, J. (2020). Perkembangan Motorik Prasekolah antara Intervensi Brain Gym dengan Puzzle. Jurnal Keperawatan Silampari, 3(2), 510-519. https://doi.org/https://doi.org/10.31539/jks.v3i2.1120

Padila, P. (2012). Buku Ajar Keperawatan Medikal Bedah. Yogyakarta: Nuha Medika

Padila, P., Andari, F. N., \& Andri, J. (2019). Hasil Skrining Perkembangan Anak Usia Toddler antara DDST dengan SDIDTK. Jurnal Keperawatan Silampari, 3(1), 244-256. https://doi.org/10.31539/jks.v3i1.809

Padila, P., Andari, F. N., Harsismanto, J., \& Andri, J. (2019). Tumbuh Kembang Anak Usia Toddler Berbasis Research. Lubuklinggau: Asra 
Primadyastuti, P. (2017). Faktor-Faktor Pemicu Dominan Terjadinya Serangan Asma pada Paien Asma. http://lib.ui.ac.id/file?file=digital/20303000-T30663\%20$\% 20$ Analisis\%20faktor.pdf. Skripsi

RSUD Dr. M. Yunus Bengkulu. (2018). Register Jumlah Kejadian Asma. RSUD Dr. M. Yunus Bengkulu

Sutini, S. (2015). Pengaruh Signifikan Pemberian Terapi Baling-Baling Bambu terhadap Status Oksigenisasi pada Pasien Asma Anak Usia Pra Sekolah di Rumah Sakit Islam Jakarta. http://lib.ui.ac.id/file?file=digital/20282677T\%20Titin\%20Sutini.pdf

Widiyatmoko, A., \& Wulanningrum, D. N. (2018). Pengaruh Terapi Bermain Super Bubbles terhadap Kecemasan akibat Hospitalisasi pada Anak Pra Sekolah di Rsud Surakarta. Universitas Muhammadiyah Surakarta 